\title{
Decreased FOXO3 within advanced human colon cancer: implications of tumour suppressor function
}

\author{
S D Savkovic ${ }^{*} 1$ \\ ${ }^{1}$ Division of Gastroenterology, Department of Medicine, Northshore University HealthSystem Research Institute, 1001 University \\ Place; Room 304, Evanston, IL 60201, USA
}

The FOXO family of transcription factors controls diverse cellular
functions, including suppression of tumour growth in numerous
tissues (Myatt and Lam, 2007). In the last decade, researchers
extensively studied the role of FOXO3 in colonic cancer cell lines,
yet its role in suppressing colonic cancer in human tissue remained
unclear. In a current study, Bullock et al (2013) demonstrated a
decreased expression of FOXO3 in a considerable number of
human colon cancer tissues, associated with advanced pathology,
recurrence, and poor survival. This novel finding demonstrates the
possible role of FOXO3 as a tumour suppressor in human colon
cancer and establishes FOXO3 as a new biomarker in evaluating
pathobiology within colonic cancer.

Uncontrolled proliferation of transformed cells, a hallmark of colon cancer progression, is associated with the activation of growth factor receptors, activation of cellular proliferative pathways, and loss of cell cycle arrest in cancer cells. Both (a) increased expression and activation of epidermal growth factor receptors and (b) activation of proliferative signalling phosphatidylinositide 3-kinase pathway have been found in human colon cancer tissue. As previously shown, both events lead to a loss of FOXO3 in colonic cancer cell lines (Kops et al, 1999; Qi et al, 2011a), providing a reason to believe their activation decreases FOXO3 found in human colonic cancer tissue. Moreover, as downstream active $\mathrm{FOXO} 3$ regulates factors responsible for cell cycle arrest (Medema et al, 2000), decreased FOXO3 within affected human tissues would lead to stimulated proliferation in colonic cancer cells. Consequently, in proliferative colonic cancer cells, decreased FOXO3 might be a phenotype critical in promoting cancer. In addition, recurrence and poor survival in colon cancer patients have been associated with mutations and impaired function of the p53 transcription factor, which interacts with FOXO3. FOXO3 interaction with wild-type p53 is critical in eliminating cells with mutations (Chung et al, 2012), while interaction with mutated p53 promotes cell cycle arrest, attenuating proliferation in colon cancer cells (Qi et al, 2011b). Therefore, impaired p53 function, dependent on a decrease in $\mathrm{FOXO}$, could promote survival and proliferation of cells harbouring mutations. Based on this combined knowledge, decreased FOXO3 in human colon cancer tissue could, in part, be responsible for uncontrolled proliferation and recurrence.

Colon cancer progression, including recurrence and metastasis, is also supported by a microenvironment enriched with inflammatory mediators and oxidative stress. As FOXO3 negatively controls inflammation, its deficiency leads to increased chemokine in immune cells as well as in colonic cells (Lin et al, 2004; Snoeks et al, 2009). Therefore, lowered FOXO3 in human colonic cancer tissue would lead to an immune environment that further fosters cancer cell growth and metastasis. Moreover, oxidative stress leading to chronic inflammation also supports colon cancer progression. In a reciprocal fashion, during cancer progression, recruited inflammatory cells further promote oxidative stress, thus enhancing proliferation, survival, and migration of cancer cells. As active FOXO3 has been found to negatively regulate oxidative stress (Kops et al, 2002; Nemoto and Finkel, 2002), ultimately, a decrease in FOXO3 within human colonic cancer tissue would lead to a microenvironment that supports proliferation, survival, and migration of colon cancer cells.

In colon cancer progression, the sustained growth of cancer cells requires high metabolic energy. As shown recently, human colon cancer tissue has an abundance of lipid droplets, a viable source of intracellular metabolic energy (Straub et al, 2010). As FOXO3 negatively regulates lipid droplet density in colonic cancer cells (Qi et al, 2013), decreased FOXO3 in human colon cancer tissue would increase lipid droplet density and the availability of metabolic energy necessary to sustain colon cancer growth. Additionally, FOXO3 controls Sirtuin6, a negative regulator of lipid metabolism (Kim et al, 2011) recently found to act as a tumour suppressor (Sebastian et al, 2012). Hence, further understanding of this newly 
identified function of $\mathrm{FOXO} 3$ as a regulator of intracellular metabolic energy in colon cancer progression is necessary.

Bullock et al's (2013) findings indicate the existence of FOXO3's tumour suppressor function in human colon cancer, providing the opportunity to establish FOXO3 as a new biomarker and stimulate FOXO3 activity as a novel pharmacological approach in treating colon cancer.

\section{ACKNOWLEDGEMENTS}

This work is supported by NIHR01-CA160809 (SDS).

\section{REFERENCES}

Bullock MD, Bruce A, Sreekumar R, Curtis N, Cheung T, Reading I, Primrose JN, Ottensmeier C, Packham GK, Thomas G, Mirnezami AH (2013) FOXO3 expression during colorectal cancer progression: biomarker potential reflects a tumour-suppressor role. Br J Cancer 109(2): 387-394.

Chung YM, Park SH, Tsai WB, Wang SY, Ikeda MA, Berek JS, Chen DJ, Hu MC (2012) FOXO3 signalling links ATM to the p53 apoptotic pathway following DNA damage. Nat Commun 3: 1000.

Kim HS, Xiao C, Wang RH, Lahusen T, Xu X, Vassilopoulos A, Vazquez-Ortiz G, Jeong WI, Park O, Ki SH, Gao B, Deng CX (2011) Hepatic-specific disruption of SIRT6 in mice results in fatty liver formation due to enhanced glycolysis and triglyceride synthesis. Cell Metab 12: 224-236.

Kops GJ, Dansen TB, Polderman PE, Saarloos I, Wirtz KW, Coffer PJ, Huang TT, Bos JL, Medema RH, Burgering BM (2002) Forkhead transcription factor FOXO3a protects quiescent cells from oxidative stress. Nature 419: 316-321.

Kops GJ, de Ruiter ND, De Vries-Smits AM, Powell DR, Bos JL, Burgering BM (1999) Direct control of the Forkhead transcription factor AFX by protein kinase B. Nature 398: 630-634.
Lin L, Hron JD, Peng SL (2004) Regulation of NF-kappaB, Th activation, and autoinflammation by the forkhead transcription factor Foxo3a. Immunity 21: 203-213.

Medema RH, Kops GJ, Bos JL, Burgering BM (2000) AFX-like Forkhead transcription factors mediate cell-cycle regulation by Ras and PKB through p27kip1. Nature 404: 782-787.

Myatt SS, Lam EW (2007) The emerging roles of forkhead box (Fox) proteins in cancer. Nat Rev Cancer 7: 847-859.

Nemoto S, Finkel T (2002) Redox regulation of forkhead proteins through a p66shc-dependent signaling pathway. Science 295: 2450-2452.

Qi W, Fitchev PS, Cornwell ML, Greenberg J, Cabe M, Weber CR, Roy HK, Crawford SE, Savkovic SD (2013) FOXO3 growth inhibition of colonic cells is dependent on intraepithelial lipid droplet density. J Biol Chem 288: 16274-16281.

Qi W, Weber CR, Wasland K, Roy H, Wali R, Joshi S, Savkovic SD (2011a) Tumor suppressor FOXO3 mediates signals from the EGF receptor to regulate proliferation of colonic cells. Am J Physiol Gastrointest Liver Physiol 300: G264-G272.

Qi W, Weber CR, Wasland K, Savkovic SD (2011b) Genistein inhibits proliferation of colon cancer cells by attenuating a negative effect of epidermal growth factor on tumor suppressor FOXO3 activity. $B M C$ Cancer 11: 219

Sebastian C, Zwaans BM, Silberman DM, Gymrek M, Goren A, Zhong L, Ram O, Truelove J, Guimaraes AR, Toiber D, Cosentino C, Greenson JK, MacDonald AI, McGlynn L, Maxwell F, Edwards J, Giacosa S, Guccione E, Weissleder R, Bernstein BE, Regev A, Shiels PG, Lombard DB, Mostoslavsky R (2012) The histone deacetylase SIRT6 is a tumor suppressor that controls cancer metabolism. Cell 151: 1185-1199.

Snoeks L, Weber CR, Wasland K, Turner JR, Vainder C, Qi W, Savkovic SD (2009) Tumor suppressor FOXO3 participates in the regulation of intestinal inflammation. Lab Invest 89: 1053-1062.

Straub BK, Herpel E, Singer S, Zimbelmann R, Breuhahn K, Macher-Goeppinger S, Warth A, Lehmann-Koch J, Longerich T, Heid H, Schirmacher P (2010) Lipid droplet-associated PAT-proteins show frequent and differential expression in neoplastic steatogenesis. Mod Pathol 23: 480-492. 